\title{
Treasures from the deep
}

\author{
Fifty years of international ocean drilling have brought enormous insights into the workings of our planet. \\ Incorporating young investigators' ideas, cooperating internationally and sharing data and samples have been key \\ to this success.
}

T he late 1960s were an exciting period, with change in societies worldwide. For geoscientists, the year 1968 is even more significant: in addition to the social upheaval, it marks the beginning of a whole new era of Earth exploration. The advent of scientific ocean drilling made accessible a vast archive of our planet's history. Five decades later, it is difficult to imagine the Earth sciences without the insights gained through the systematic exploration of the bottom of the oceans. The concepts of continental drift and seafloor renewal at rifts were firmly established with the help of samples from the earliest explorations. Since then, drill cores from the seafloor have illuminated the processes of oceanic crust formation and subduction, and have laid the foundations of fields as diverse as palaeoceanography and deep biosphere research (Bickle, M. J., Pälike, H. \&

Teagle D. A. H. Nat. Geosci. 4, 3-4; 2011).

In the 50 years of international ocean drilling, more than 10,000 programme-related scientific papers have been published (https:// go.nature.com/2PD2vHk), and more than 500 of those articles appeared in Nature and Science. At Nature Geoscience, we are proud to have hosted 69 ocean-drilling-related papers since our launch in 2008 , and as many as Nature and Science combined since 2014. A meeting to celebrate the 50th anniversary of the first drilling and coring cruise at the Natural History Museum in London at the end of September brought to light some of the ingredients that made the programme such a resounding - and ongoing - success.

First, opportunities at an early stage of their career to take on responsibility, develop their skills and pursue their own research ideas were gratefully acknowledged by several of the speakers. Some of these instances originated from necessity, for example on cruises where the range of required expertise was not fully covered by the team of researchers on board. This has opened the chance for young scientists to step up, sharpen their skills and broaden their horizon. However, for many, responsibility also came by design. Not-yetestablished scientists have the chance to put forward a proposal, and provided they have ship-board experience, also to lead a cruise. Most importantly, proposals are evaluated

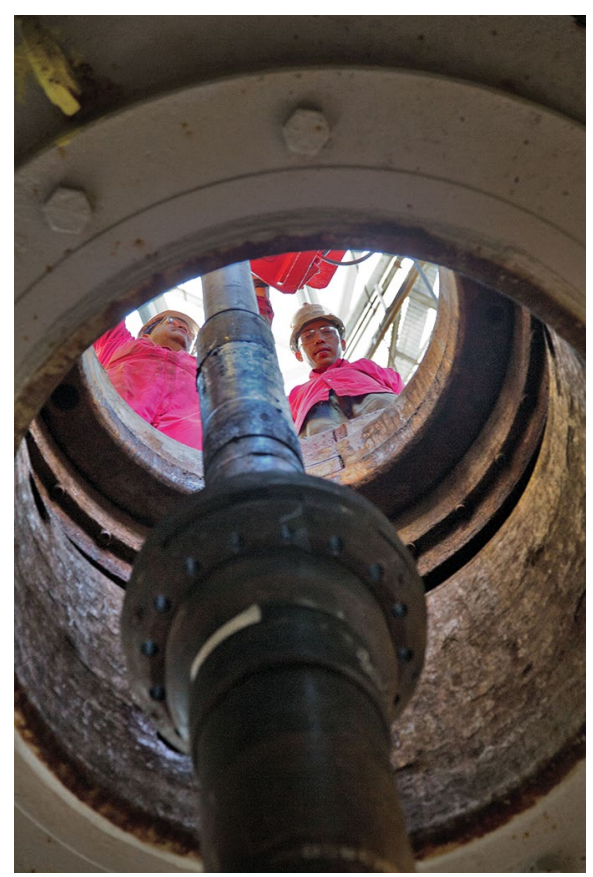

Credit: WILLIAM CRAWFORD, JOIDES RESOLUTION SCIENCE OPERATOR, IODP

on scientific promise and feasibility, and not on the proposer's track record.

Making the most of the fresh ideas generated by the people who enter a field of research is key to progress anywhere. Affording independence and responsibility early on has helped the scientific drilling community in this endeavour. Combined with the camaraderie that comes with sharing the confined space of a research vessel with a limited number of people for many weeks, the principle of early independence has allowed many young researchers to develop their novel ideas. And in time, they have turned into engaged, knowledgeable leaders that now nurture the next generation of scientists.

Secondly, international cooperation has been instrumental to success. After its early few years as a United States (US)-based programme, the Deep Sea Drilling Project - the first of the three consecutive ocean drilling programmes since 1968 - turned international in 1975 when the Federal Republic of Germany, Japan, the United Kingdom, the Soviet Union and France joined in both field work and post-cruise science analyses. Its successors, the Ocean Drilling Program (ODP; 1985-2004), the Integrated Ocean Drilling Program (IODP; 2004-2013) and the International Ocean Discovery Program (IODP; from 2013), have broadened the base of participation. The number of members has now expanded to more than 20 countries that span North and South America, Europe, Asia and Australia/New Zealand.

The sheer enormity of the task - drilling cores in all ocean basins from a floating ship, thousands of metres below the sea surface into the sediments and underlying crust requires resources and technical know-how that one country would find hard to assemble and maintain over five decades. International collaboration has also ensured that a diverse taskforce of scientists from around the globe have chipped in with analysing the data and samples, both on-board and on the shore.

Finally, strategies for sample and data archiving and sharing are carefully thoughtout, and exemplary in the way they serve the community. In terms of the actual cores, material is carefully archived and curated in three centres in the US, Germany and Japan. Samples are released in steps, first to the science party of a cruise, and then to all researchers upon request and review by an advisory board. As a result, the hard-won samples are used to their full potential.

Data sharing is at the heart of the programme. It is no coincidence that a scientist who confessed to getting sea-sick on a 4-mile ferry crossing spoke at the London meeting about data obtained through deepsea drilling: to access the data he never had to board a ship. Because it is mandatory to make data available, they are analysed way beyond the community of sea-going scientists.

In the geosciences, obtaining valuable samples and data often involves expensive expeditions, exploration of new territories and techniques and - last but not least time spent away from family and friends. It is good practice to ensure, to the best of our abilities, that we wring as much scientific insight from those explorations as we possibly can. The lessons learned through the succession of ocean drilling programmes can help achieve maximum gains more broadly. $\square$

Published online: 30 October 2018 https://doi.org/10.1038/s41561-018-0260-z 